\title{
Psychological Needs of Female Students of Hussein Bin Talal University and Their Relation to the Mothers' Education and Work as A Model
}

\author{
Dr. Etaf M. Al-Kfaween \\ Department of psychology, Faculty of education, Tafila technical university, Tafila, Jordan \\ E-mail: EtafK2016@Gmail.com
}

Received: Sep. 28, 2019

Accepted: Oct. 28, 2019

Published: November 1, 2019

doi:10.5296/jse.v9i4.15528

URL: https://doi.org/10.5296/jse.v9i4.15528

\begin{abstract}
The present study aimed to identify the level of psychological needs of students of Al-Hussein Bin Talal University and its relationship to the mother's education level and work in addition to the academic specialization of the students, and to achieve the goal of the study a random female students sample was selected from the university which reached (176) students, the psychological needs scale was used, the results indicated that the level of psychological needs of the student was in the average level, and the differences were statistically significant among the students, according to the work of the mother in the dimensions of the psychological needs scale where the differences in the need for independence and the need for competence for the benefit of the working mothers children, and the need for belonging for the benefit of non-working mothers, and the differences between the students in the level of psychological needs according to the mother's education were not statistically significant except for the need to belong, the differences were in favor of low mother education, the differences between the sample was statistically significant according to the variable of academic specialization, the differences in the need for independence and the need for competence were for the benefit of scientific colleges and the need for belonging was for the benefit of humanities colleges, the study recommended the work of courses for university students to develop their psychological needs.
\end{abstract}

Keywords: Psychological needs, Independence, Competence, Belonging, Mother's education, Mother work, Academic specialization 


\section{Introduction}

The current era witnesses rapid changes in all aspects of life as evidenced by the revolution in the means of communication and technology, affecting the lives of the individual and the nature of the decisions taken to face the life challenges so that he can achieve the proper psychological adjustment and because the female suffers through life from stereotypes regarding what possessed Skills (Lockwood,2006) these life changes have posed a great challenge for females in particular, requiring them to acquire a lot of skills and needs to be able to adapt to these changes, the need for physical independence and independence in decision-making and characterized by the decision-making process has become necessary to possess, and build positive relationships with others. Others should be attentive, as they seek to achieve themselves. Because the family environment is an important incentive for females to provide support and encouragement to help females to grow and develop it has been modified by many of the strategies of the psychological support assistant charges for which required psychological balance and is a parent through the growth stages in different aspects of the sons life of a source for modeling a lot of behaviors that will help them during the process and development in the face of attitudes and life providing social support and show empathy for the individual, that the individual leads to a sense of pride and efficiency . (Berk, 1999).

And the level of parental education affects the growth of children and thinking process on how they face their life situations ( Sharif, 2014 ), as the initial mother and son relationship within the uterine environment, where some researchers believe that every thought the mother get has a direct effect the fetus, then the breastfeeding stage is one of the most important stages of development where the basic principles of personal growth (AboJado,2004) are formed and the impact of the mother on children continues through the different stages of growth in general and for females in particular because females are more likely to be affected by the female model (Lockwood,2006), the effect is less inclined for the stay at home mothers, (Ades, 2005), as the working mother gives her children the freedom to practice independence and self-reliance, which contributes to their development process and build their personalities better (Berk, 1999) because they are giving them the freedom to satisfy their need for independence and the need for efficiency through the decisions they make in the environment, which reflect how to satisfy the needs of belonging through interaction with others to achieve a psychological balance required.

The self-determination theory indicated that there are three types of needs that are necessary for the individual:

- The need for independence, where the sense of the individual that he is able to take his decision separately from others.

- The need for competence is the perception of the individual that the resulting behavior in life situations is effective.

- The need to belong is the desire of an individual to be accepted by others and has a group to which it belongs and the theory of self - determination suggests that to satisfy the 
psychological needs of independence.(Andyno,2015).

Competence and affiliation is working to provide the support for the individual's ability to possess the flexibility to meet the requirements of life and working to protect him from the injury of uncomfortable feelings. (Bunc, Londale, King,Childs\& Bennie) .

That satiating the need for independence and the need for competence is one of the best ways to provide a suitable environment for students to facilitate their transition from one stage to another. (Gillison, Standage \&Skevington, 2010).

Murray has pointed out that the need directs the behavior where it considered that the need for sovereignty means the individual's desire to impose authority on others, and the need for independence is the desire to live according to the way of own choosing, and the need to belong an individual's desire to be part of a group of people. The need to accomplish is the desire to stand out from others and act in an efficient manner. (Rabeea, 2013).

Maslow had another point of view when studying the human nature where he put the classification of humanitarian needs and arrange them in hierarchy starting from the bottom of the pyramid physiological needs and security needs and here the individual looking for conditions that provide him with safety and hence the need to love and belong, a search for the presence with others and the need to be part of the group to which they belong.(Beck,2000) And then the need for self-esteem is a sense of confidence, efficiency, independence and a sense of freedom, then comes the need for knowledge is an individual's quest to have an understanding that constitutes his need for self-fulfillment and is seeking to satisfy the individual's ability to reach what he wants.(Petri,1996).

When Reiss studied the psychological needs of the individual he used the concept of desire, where he pointed out that the behavior of the individual is directed at sixteen basic desires to lead his goals in life and the process of satisfying those desires are influenced by the environment in which the individual lives and experiences, as well as culture prevailing in society, the strategies used with the individual can raise the level of desire or may lead to a lower level. (AL-kfaween,2003)and one of these desires that are talked about is the desire of independence which is the desire of the individual's access to freedom and self - reliance and the desire for social relationships, a sense of the individual when he was comfortable with the others, and the desire for power and is the individual's sense of satisfaction when controlling others. The individual may suffer from poor communication with others in the environment in which they live due to the different order of desires in individuals. (Reiss,2000) .

Therefore the need to provide the environment of psychological models needed by the individual during the growth period, an idea that the Pandora theory was based on where it was focused on the concept of modeling and that the individual might imitate the behavior that has approval and acceptance during the process of interaction with others, the social environment which the individual interacts through with parents and friends acquires the individual's different behaviors as well as learning a lot of strategies which they can build a 
cultural self - sufficiency and self-confidence to acquire the skill of self - image management, which ensures him access to achieve the goals they seek to achieve.( Pintich\& Schunk, 1996) If the models that the individual resort to imitate are efficient they make the individual possess the skills to develop his behavior for the better. The more attractive the model is to the individual, the greater the focus of the individual's attention on it and therefore the more inclined to imitate.( Petri,1996) And because the family environment affect the psychological adjustment of the individual process (Sharif, 2014) has pointed out to the importance of the level of education for parents were positively affects the proper psychological growth of the individual and evolve properly during the process of interaction with the environment.

The focus of parents on success encourages the individual to become more independent and self-reliant and contributes to the development of self-efficacy skills because the individual's feelings of success or failure reflects the basic psychological structure found in the self that was acquired during the growth process(Al-kfaween,2003) because females are more affected by the stereotype of others regarding the possession of skills in completing the work efficiently, studies have indicated that females are more affected by the female role model, (Lockwood,2006), Hoffman it has been pointed out that the mother's work affects children through:

1-Reduce the molding of child models and stereotypes.

2-The mother working leads to the fact that their children have the ability to be independent more in their different live matters than non - working mother children. The working mother understands the importance of her role in raising children

3-And give the individual more opportunity to take responsibility and a sense of independence. (Ades, 2005). The female children of the working mother have a sense of the importance of the role played by women in life as the role is greater than just a decision or a sense of freedom it is a state of achievement and success and progress in the job. (Berk, 1999)

The researchers talked about the importance of the prevailing relationship between the mother and her children where the balanced relationship contributes to building maximum level of adaptation and productivity and the ability to face various challenges, (Al-kfaween,2010)and as our society has become more focused on the empowerment of females by providing opportunities for them to achieve independence in decision - making and the efficiency of those decisions and satisfy the need to belong to face the future obstacles successfully this study was aimed at identifying the psychological needs of university students and their relationship to the mother's education and work as a role model

\section{These are some of the studies and what is referred}

The study of Alzghol, Dab obi, Abdurrahman (2019) which aimed to identify the psychological needs and its relationship to happiness when a sample of students of Yarmouk University, the sample of the study reached (3390) students, where the psychological needs measure and Oxford list of happiness was used. The results indicated that there was a 
correlation between psychological needs, efficiency, independence, belonging and happiness. The differences in psychological needs according to the specialization variable were statistically insignificant except for the need for competence; the differences were statistically significant for the benefit of students of human specialization.

In a study Jufri, Akib, Ridjal,Sahabuddin \& Said (2018) where the aim was to identify the impact of the family environment on entrepreneurship among a sample of students of vocational schools amounted to (369) students, where the results showed that there is a statistically significant impact of the family environment in influencing students' attitudes towards entrepreneurship.

In the study Hall, Mcnallie, Timmer,Wilson, Custers \&,Bulck (2017), which aimed to identify the impact of family relations prevailing on the process of adjustment among a sample of first year students at the university where the sample of the study (944) students from two different cultures are American students and students from Belgium, where the results indicated that the family environment It is characterized by positive relations working to improve the process of adaptation of the student in the university environment and raise their self-competence.

The study Barcat (2016), which aimed to identify the skills of working, and non-working mother and its relationship to self- management in children, the study used the measure of maternal parenting skills and measure of self-management of children, and questionnaire family information. The results indicated that the differences in the self-management of children according to the mother's education variable were statistically significant and in favor of the children of mothers with higher achievement. The differences in self-management of the children of the working mother and non-working mother were significant for the benefit of the working mother.

The study Ummet (2015) aimed to identify self-esteem and its relationship to psychological needs of a sample of university students reached (342) where the results indicated that there is a positive correlation between the satisfaction of the need for belonging and the need for independence and self-esteem, but the need for competence does not have a link With self esteem, the differences were statistically significant in the level of self - esteem depending on mother 's education level and income level .

The study Omar( 2014) which aimed to identify the social and psychological needs of a sample of female students of King Saud University reached (130) students, where the results indicated that the need for security, love, belonging, acceptance and independence saturated among female students.

Saleem, (2012) conducted a study aimed at identifying the relationship between the need for autonomy and self-concept among working and non-working mother children. The sample of the study reached (112) children, including (56) females and (56) males. There are statistically significant differences in the need for independence and for the benefit of males from working mothers and females to non - working mothers.

The study Qatnani (2011), which aimed to identify the relationship between psychological 
needs and the concept of self and the level of ambition among university students, where the sample was conducted by the study (530) students, has used a measure of psychological needs and another for the concept of self as well as a measure of the level of ambition. The results showed that the differences between the students of the scientific and literary colleges were statistically significant in the need to belong and for the benefit of the literary colleges. The differences are not statistically significant between students of literary colleges and students of scientific colleges in the need for independence and competence

The study Jardat (2007), which aimed to identify the level of parents' education and family income and its relationship to the choice of children for university specialization, the sample of the study reached (1416) male and female students undergraduate in Jordanian universities. The results indicated that there is a positive correlation between the high educational level of the father and mother and the choice of children for the scientific specialization.

Where the study AL-Orabei (1995), which aimed to identify the relationship between academic achievement of the students and the social and economic center of the family and family stability, the sample of the study reached (500) students from King Saud University, the results indicated that there is no correlation between the level of achievement and the level of achievement the mother

The study Hill (1995) aimed to know the impact of the method used by the father or the mother and the family environment where the sample of the study reached ( 174 ) male and female students. The results indicated that the authoritarian parental style positively correlated with the control negatively correlated with freedom of expression and a sense of independence. With positive affiliation, organization and achievement, the parental style of tolerance was positively associated with free speech.

\section{Study Importance}

Many researchers focus on the interest in a supportive environment which females can exploit their abilities and energies to the fullest extent possible so that they can efficiently pursue the goals they seek. An important thing is the psychological models available in the environment which the behavior acquires and arouses social as well as psychological need, and in our environment we need such studies and therefore this study seeks to:

1- Attempt to reveal the extent of the level of education of the mother and her work in determining the level of psychological needs of independence, competence and belonging to university students.

2-The study sheds highlights on the importance of psychological needs (independence, competence and affiliation) among female students where they are linked to their daily lives and decisions that they talk in the face of the future.

3-It is considered as new study that has not been studied by researchers within the limits of science research. 


\section{1) Macrothink}

\section{Study purpose}

1- Identify the level of psychological needs of Hussein bin Talal University students. 2Determine the nature of the relationship between psychological needs and the level of education of the mother, the work of the mother as a female role model.

3 - Identify the psychological needs prevailing among university students according to academic specialization

\section{Study Questions}

1- What is the level of psychological needs (independence, competence, and belonging) among students of Al-Hussein Bin Talal University?

2 - Are there any significant statistical differences between the students of Al - Hussein University in the level of psychological needs (independence, competence, and belonging) according to the variable of the mother's work?

3 - Are there any statistical differences between the students of Al - Hussein University in the level of psychological needs (independence, competence, and belonging) according to the variable level f mother's education?

4 - Are there any statistical differences between the students of Hussein University in the level of psychological needs (independence, competence, and belonging) according to the variable of academic specialization?

\section{Method}

\subsection{Study Design}

This study is considered as a descriptive study.

\subsection{Study Statistics:}

-To answer the study related questions and calculating the means and standards deviation

-To know the differences among the study variables and use the T test, one way ANOVA and Scheffe test.

\subsection{Study society and sample}

The research community consisted of all bachelor students in scientific colleges (engineering, technology, nursing and science) and humanities (literature, educational sciences, administrative sciences and archeology) in the housing of Hussein Bin Talal University and registered for the first semester, and the number of (1459) student,(176) students has been selected in a random manner, where the percentage was as follows.

\begin{tabular}{lll}
\hline Study society & Study sample & Percentage \\
\hline 1459 & 176 & $12 \%$ \\
\hline
\end{tabular}




\section{Ml Macrothink}

\subsection{Study Scale}

The study scale consisted of two parts:

The first part includes the student's personal information questions:

- Mother's work (working) (not working)

- Mother's Education 1- Secondary or Less (Low) 2- Intermediate Diploma (Intermediate)

3- Bachelor (High)

Academic specialization: 1- Scientific colleges 2- Humanities colleges

Part II Psychological Needs Scale

The Psychiatric Needs Scale (Deci and Ryani, 1999) was used, which was used by many researchers, where (Eilyan, 2005) prepared and translated to Arabic, and (Qatnani, 2011) applied in the Palestinian environment.

The standard consists of (27) words from multiple choice, five of which are selected (A, B, C, D, and E). Some phrases have a choice consisting of (A, B, C, and D). Some phrases bear a negative character in the answer class as follows $(5,4,3,2,1)$, and other paragraphs bear the positive character of the answer gets Screened on the class as follows $(5,3.4,2,1)$. Which indicates the high class High needs and low score at low level of needs.

\section{Results}

To know the level of Psychological needs (independence, belonging, competence) was calculated the mean and stand deviation grades of the students in the sample as shown in table 1 .

Table 1. Means and standard deviation for the grads of the students in the sample on the scale of Psychology needs and dimension

\begin{tabular}{llll}
\hline Variable & $\mathrm{N}$ & Mean & Std Deviation \\
\hline Psychological needs & 176 & 3.102 & .1797 \\
Independence & 176 & 3.203 & .3527 \\
Belonging & 176 & 2.843 & .4699 \\
Competence & 176 & .3 .261 & .1797 \\
\hline
\end{tabular}

To find whether there are any differences in the Psychological needs (independence, belonging, competence) between the students' of the study sample's psychological needs and mother work, the means and stand deviation where collected, in addition to finding the known differences, the T test was conducted which the Table 2 shows. 


\section{Macrothink}

Journal of Studies in Education

ISSN 2162-6952

2019, Vol. 9, No. 4

Table 2. The results of the $\mathrm{T}$ test for the Psychological needs and of the sample in the light mother work variable.

\begin{tabular}{lllllll}
\hline Dimensions & Mother & Mean & $\begin{array}{l}\text { Std } \\
\text { Deviation } \\
\text { work }\end{array}$ & T & df & Sig \\
Independence & Work & 3.288 & .3639 & 3.465 & 174 & .001 \\
& Not work & 3.109 & .3163 & & & \\
Belonging & Work & 2.681 & .4833 & 5.09 & 174 & .000 \\
Competence & Not work & 3.019 & .3863 & 2.70 & 174 & .008 \\
Psychological & Work & 3.342 & .4180 & .154 & 174 & .878 \\
needs & Not work & 3.171 & .4223 & & & \\
& Work & 3.104 & .1938 & & & \\
& Not work & 3.100 & .1639 & & &
\end{tabular}

To know the differences between the psychological needs and mother education means and standard deviations for the grades of students in the sample were calculated as shown in table 3 .

Table 3. The results of the one way ANOVA for the psychology needs and mother education of the sample.

\begin{tabular}{|c|c|c|c|c|c|}
\hline Sours & $\begin{array}{ll}\text { Sum of } \\
\text { Squares }\end{array}$ & $\begin{array}{l}\text { Mean } \\
\text { Square }\end{array}$ & $\mathrm{F}$ & df & Sig \\
\hline Mother & .157 & .079 & 2.477 & 2 & .087 \\
\hline education & 5.494 & .032 & & 173 & \\
\hline Error & 1699.395 & & & 176 & \\
\hline Total & 5.652 & & & 175 & \\
\hline \multicolumn{6}{|l|}{ Corrected } \\
\hline Total & & & & & \\
\hline
\end{tabular}

To know the differences between the independence need and mother education means and standard deviations for the grades of students in the sample were calculated as shown in table 4.

Table 4. The results of the one way ANOVA for the Independence need and mother education of the sample.

\begin{tabular}{|c|c|c|c|c|c|}
\hline Sours & $\begin{array}{ll}\text { Sum of } \\
\text { Squares }\end{array}$ & $\begin{array}{l}\text { Mean } \\
\text { Square }\end{array}$ & $\mathrm{F}$ & df & Sig \\
\hline Mother & .302 & .151 & 2.477 & 2 & .298 \\
\hline education & 21.462 & .124 & & 173 & \\
\hline Error & 1827.704 & & & 176 & \\
\hline Total & 21.764 & & & 175 & \\
\hline \multicolumn{6}{|l|}{ Corrected } \\
\hline Total & & & & & \\
\hline
\end{tabular}


To know the differences between the belonging need and mother education means and standard deviations for the grades of students in the sample were calculated as shown in table 5

Table 5. The results of the one way ANOVA for the Belonging needs and mother education of the sample.

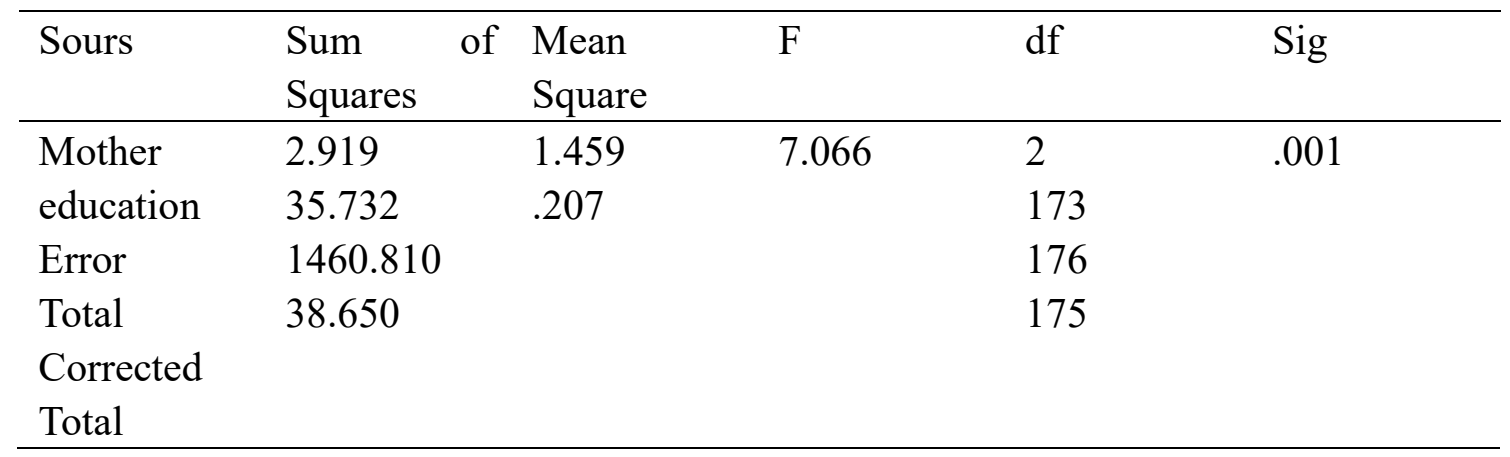

To know the differences between the competence need and mother education means and standard deviations for the grades of students in the sample were calculated as shown in table 6.

Table 6. The results of the one way ANOVA for the Competence need and mother education of the sample.

\begin{tabular}{|c|c|c|c|c|c|}
\hline Sours & $\begin{array}{ll}\text { Sum of } \\
\text { Squares }\end{array}$ & $\begin{array}{l}\text { Mean } \\
\text { Square }\end{array}$ & $\mathrm{F}$ & $\mathrm{df}$ & Sig \\
\hline Mother & 1.749 & .874 & 2.477 & 2 & .008 \\
\hline education & 30.247 & .175 & & 173 & \\
\hline Error & 1903.203 & & & 176 & \\
\hline Total & 31.996 & & & 175 & \\
\hline \multicolumn{6}{|l|}{ Corrected } \\
\hline Total & & & & & \\
\hline
\end{tabular}

The result of Scheffe test to know the differences between the mother education level (Secondary and less, Diploma, Bachelor ) of the sample as shown in table 6.

Table 6. The results of the Scheffe test for the Mother education level (Secondary and less, Diploma, Bachelor) of the sample.

\begin{tabular}{lccc}
\hline Mother education & Bachelor & Diploma & Secondary and less \\
\hline 3.393 & & & \\
Secondary and less & $* .3201$ & - & - \\
Diploma & .185 & -185 & $* .3201$ \\
3.358 & & & \\
Bachelor & & & \\
3.320 & & & \\
\hline
\end{tabular}

To find whether there are any differences among the subjects of the study sample in the psychological needs level and its dimensions according to the academic specialization 
variable, the means and stand deviation where collected in addition to finding the known differences the T test was conducted which the Table 8 shows .

Table 8 . The results of the $\mathrm{T}$ test for the level of psychology needs and it dimensions in the light Academic specialization variable.

\begin{tabular}{lllllll}
\hline Dimensions & Specialization & Mean & $\begin{array}{l}\text { Std } \\
\text { Deviation }\end{array}$ & $\mathrm{T}$ & $\mathrm{df}$ & $\mathrm{Sig}$ \\
\hline Independence & Scientific & 3.360 & .3352 & 7.846 & 174 & .000 \\
& Humanity & 2.997 & .2258 & & & \\
Belonging & Scientific & 2.603 & .3567 & 9.552 & 174 & .000 \\
& Humanity & 3.157 & .2504 & & & \\
Competence & Scientific & 3.510 & .3322 & 11.932 & 174 & .000 \\
& Humanity & 2.932 & .2982 & & & \\
& & & & & & \\
Psychology & Scientific & 3.157 & .1868 & 5.012 & 174 & .000 \\
needs & Humanity & 3.029 & .1406 & & & \\
& & & & & & \\
\hline
\end{tabular}

\section{The results discussion}

The results showed that the level of psychological needs of the study sample was average on the scale as a whole and on the dimensions (independence, competence and belonging). This can be attributed to the nature of the strategies used by parents with the student during the process of socialization, while the nature of the environment in which we live governed by customs and traditions and therefore females are subjected to many restrictions as they remain belonging to the guardian, whether the father, brother, or spouse, therefore doesn't enjoy independence in their own decision - making, and because the restrictions limit their opportunity to test their competence in many of the positions and challenges affected her level of competence, and because the restrictions are more in social relations the parents allow or doesn't allow them to choose their friends and thus are the ones who determine their friends, that impacted the need of belonging of the sample individuals. And the results of this study were agreed with the study (Jufri, Akib, Ridjal Sahabudin \&Said) where the results showed that there is a statistically significant impact of the family environment. And the study (Hall, Mcnallie, Timmer, Wilson, Custers \&Bulck,2017) Focusing to the family environment role.

As for the question which examines the differences between the sample members according to the mother's work variable, the results indicated that the differences in the psychological needs scale were not statistically significant and were statistically significant in the dimensions of the scale where the differences in the need for independence were in favor of female students from the working mother as well as the need of competence differences was 
in favor of female students from a mother who is working and can be attributed to the fact that the working mother who are concerned with her jobs give the opportunity for their children to rely on their selves may resort to assigning some female to help in food preparation or house cleaning or tutoring her brothers so she took the responsibility of the house matters, role and experiences which increases the competence of the individual on the other hand, the mother models the feminine model for females and therefore resort to mimic the female behavior in terms of self - reliance and participation in the family business

As for the need to belong, the results showed that the differences in favor of the students from the non-working mother can be attributed to that the non-working mother has spare time and thus can spend a lot of time with friends and exchange visits and meet the invitations of events and therefore because the female imitates the behavior of the mother, the environment were they grew in was focused on the importance of social relations and interaction with others, the differences where to their advantage. And the result of this study were agreed with the study (Salim,2012) As for the answer to the question of whether there are differences due to the variable level of mother's education, the results indicated that the differences are not statistically significant except for the need to belong to the mother in favor of secondary or lower education level. Others need to receive friends and meet invitations. The need for independence and the need for competence were not significant because the restrictions as mentioned above are imposed on females of society regardless of whether they are educated or not, but females with higher education may have some opportunities for independence. And the result of this study were disagree with the study (Barkat,2016).

As for the question of whether there are significant differences in the academic specialization variable, the results indicated that the differences were statistically significant on the scale as a whole and on the dimensions, the results were for the benefit of scientific colleges in competence and independence and humanity colleges in need of belong, and the result of this study were agreed with study (Qatnani,2011) and disagree with study (Al-Zghol, Dab obi, Abdurrahman, 2019) in can be attributed to the fact that the family and community members look to college students with a lot of sense of pride, appreciation and respect and therefore students feel the scientific colleges courage and strength in making life decisions and trying unlike the students of humanitarian colleges who focus on the humanitarian aspect in life and in the view and interaction with others.

\section{Recommendations}

1 - The study recommends the creation of awareness programs for parents to help them in adjusting the methods used in the socialization of females in order to help them in raising the level of their psychological needs.

2 - Focus on encouraging teachers and at all levels of education to use strategies that work to develop the psychological needs of females.

3 - Conduct courses for university students in order to develop the psychological needs and increase their awareness of interest in them. 


\section{References}

Abo - jado, Saleh Mohammed. (2004). Psychology of Socialization. Dar Amassira, Amman, Jordan.

Ades, Abedalhman. (2005). Educational Psychology. Dar Alfiker, Amman,Jordan.

AL-Kfaween,Etaf .(2003). The Effect of Teaching - Learning Program on the adjustment level Basic Desires of the tenth grade students in Amman . Jordan, PhD Theses.

Al- Kfaween, Etaf (2010) Social Competence among the Students of the University and Relation to Demographic Factors. European Journal of Social Sciences, 16(1), 160-166.

Al-kfaween, Etaf. (2010). Self- efficacy Among the Students of the University and Relation to Gender and Specialization. European Journal of Scientific Research, 6(3), 416-421.

Andyno. Maryan. (2015). Personality Psychology. Al-hrbee. Nauef, Translated book. Dar Amassira Amman, Jordan.

Al-orabei, Hekmat. (1995). The relationship of the academic achievement of the university student with some family variables. Journal of King Saud University, 7(1), 133-162.

Alzghol,Rafea., Dab obi, Khldoon., \& Abdurahman, bdesalam.(2019). Psychological needs in the light of the theory of self-identification and its relationship to happiness among students of Yarmouk University. Journal of Studies, 46(1), 47-61.

Beck, Robert C. (2000). Motivation, Theories and Principles. Prentic Hall, USA.

Bercat, Tgreed Siaed. (2016). Parental skills of mothers and their relationship to self-management in their teenagers. Alexandra Journal of Agricultural Sciences, 61(3), 311-339.

Berk, Laura E. (1999). Infants Children and Adolescents. Allyn and Bacon, USA.

Bunc,L.,Lonsadale AJ., King N.,A, Childs J., \& Bennie R .(2019). Emotional Intelligence and Self determined Behaviour Reduce Psychological Distress Interactions with Resilience IN social Work Students in the UK.. British Journal of Social Work, 46(3), 416-421. https://doi.org/10.1093/bjsw/bcz008

Gillison Fina, Standage Martyn., \& Skevington Suzanne. (2010). Chang in Quality Life and Psychology need Satisfaction following the transition to Secondary School . Educational Psychology, 78(1), 149-162.

Hall. Elizabeth, Mcnllie.Jenna, Custers Katheen, Timmer mans Elizabeth, Wilson Steven, \& Bulck Jan Vanden. (2017). Across- cultural Examination of the Mediating Role of Family Support and Parental Advice Quality on the Relationship Between Family Communication Patterns and First years College Students Adjustment in United states and Belgium . Communication Research, 44(5), 638-667. https://doi.org/10.1177\%2F0093650216657755

Hill. Nancy. (1995).The Relationship Between Family Environment and Parenting Style : A preliminary Study of African American Families. Journal of Black Psychology, 21(4), 
408-423.

Jardat, Mohammed. (2007). Relation of parents 'education level and family income to male and female choice of university specialties. Journal of Studies, 34(1), 90-106.

Jufri, Muhammad, Akib, Haedar, Ridjal Symsu, Sahabuddin Romansyah, \& Said Farid. (2018). Improving Attitudes and Entrepreneurial Behavior of Students Based on Family Environment Factors at vocational High School in Makassar School. Journal of Entrepreneurship Education, 21(2).

Lockwood, Penelope. (2006). Some Like Me Can Be Successful: Do College Students Need Same-gender Role Models. Psychology of Women Quarterly, 30(1), 36-46.

Omer Ahlam Alatta.(2014). The most important social and psychological needs among Saudi Arabia university students and the extent of perfusion, a study applied to a sample of students at King Saud University. Social Journal, (8), 101-156.

Petri, Herbert L. (1996). Motivation, Theory, Research, and Applications. Brooks- Cole Publishing Company. USA.

Pinterich, Paul R. Schunk, Dale H. (1996). Motivation in Education, Theory, Research, And, Applications. Prentice Hall Inc USA.

Qtnani,Alae (2012). Psychological needs and the Self- concept and their Relationship with the Level of Ambition among AL- zhar University Students in Gaza. Master Theses. Gaza.

Rbeea, Mohammed, Shahte. (2013). Personality Psychology. Dar Amassira Amman, Jordan.

Reiss,Steven. (2000). Who Am I? The 16 Basic Desires That Motivate Our Action and Define Our Personalities. Penguin Putnam Inc USA.

Seleem, Amel Dawoed. (2012). The Relationship of Autonomy with the Self - concept in children of working and non-working mothers. Journal of College of education for woman. 23(2), 599-620.

Sharif, Laiela. (2014). Parents' Efficiency in Education from the Viewpoint of Children. Journal of Damascus University, 30(2), 47-80.

Ummet Durmus. (2015). Self esteem among College Students: A study of Satisfaction of basic Psychology needs and some variables. Procedia- Social and Behavioral Sciences. 174(2015), 1623-1629. https://doi.org/10.1016/j.sbspro.2015.01.813 